\title{
habilidade Competitiva de Cultivares de Trigo com Plantas DANINHAS $^{1}$
}

\author{
Competitive Ability of Wheat Cultivars against Weeds
}

LAMEGO, F.P. ${ }^{2}$, RUCHEL, Q. ${ }^{3}$, KASPARY, T.E. ${ }^{4}$, GALLON, M. ${ }^{5}$, BASSO, C.J. ${ }^{6}$ e SANTI, A.L. ${ }^{7}$

\begin{abstract}
RESUMO - A habilidade competitiva constitui-se em importante ferramenta para o manejo integrado de plantas daninhas. Objetivou-se com este trabalho avaliar o potencial de cultivares de trigo em competir com as plantas daninhas azevém e nabo, em diferentes periodos de convivência. O delineamento experimental foi o de blocos ao acaso, arranjado em esquema fatorial $4 \times 2 \times 3$, com três repetições. No fator A alocaram-se os cultivares de trigo (BRS Guamirim - ciclo precoce e estatura baixa; Fundacep Cristalino - ciclo precoce e estatura média; Fundacep Raízes - ciclo médio e estatura média; e BRS 296 - ciclo precoce e estatura alta); no B, a ausência ou presença de controle das espécies daninhas; e no C, a época de manejo das plantas daninhas (todo o ciclo da cultura ou até a colheita, até 15 dias após a semeadura e até 30 dias após a semeadura - DAS). O cultivar Fundacep Cristalino, precoce e de estatura média, demonstrou maior habilidade competitiva do que o azevém e o nabo, quando comparado aos demais cultivares, em todos os periodos avaliados. O controle das plantas daninhas em trigo deve ser realizado precocemente, em especial para cultivares com menor habilidade competitiva.
\end{abstract}

Palavras-chave: Triticum aestivum, Lolium multiflorum, Raphanus raphanistrum, interferência.

\begin{abstract}
Competitive ability is an important tool for integrated weed management. The objective of this work was to evaluate the potential of wheat cultivars in competing with the weeds Italian ryegrass and wild radish, at different periods of coexistence. The experiment was arranged in a randomized block design, in a factorial scheme $4 \times 2 \times 3$, with three replicates. The following wheat cultivars were allocated in Factor A: BRS Guamirin - short cycle and short plant height; Fundacep Cristalino - short cycle and medium plant height; Fundacep Raizes - medium cycle and medium plant height; and BRS 296 - short cycle and tall plant height. In Factor B, absence or presence of weed control, and in Factor $C$, weed management time (throughout the crop cycle or until pre-harvest, up to 15 days after seeding and 30 days after seeding - DAS). The Fundacep Cristalino cultivar - short cycle and medium plant height- showed more competitive ability than the Italian ryegrass and wild radish, compared to the other cultivars, in all the periods evaluated. Weed control in wheat must be performed early, especially for cultivars with lower competitive ability.
\end{abstract}

Keywords: Triticum aestivum, Lolium multiflorum, Raphanus raphanistrum, interference.

1 Recebido para publicação em 27.7.2012 e aprovado em 13.11.2012.

2 Eng-agr-Ar ${ }^{\mathrm{a}}$., Dra., Prof ${ }^{\mathrm{a}}$. do Dep. de Ciências Agronômicas e Ambientais da Universidade Federal de Santa Maria-UFSM/Cesnors, Linha Sete de Setembro s/n, BR 386, Km 40, Frederico Westphalen-RS, <fabilamego@yahoo.com.br>; ${ }^{3}$ Eng ${ }^{\underline{a}}-A g r{ }^{\underline{a}}$., Mestranda do PPG em Fitossanidade, Universidade Federal de Pelotas - UFPel, <queli.ruchel@yahoo.com.br>; ${ }^{4}$ Eng ${ }^{\circ}-A_{g r}{ }^{\circ}$., Mestrando do PPGAAA - Programa de Pós-Graduacão em Agronomia: Agricultura e Ambiente, UFSM/Cesnors, <tiagokaspary@hotmail.com>; ${ }^{5}$ Graduando do Curso de Agronomia, UFSM/Cesnors, <mateusgallon@hotmail.com>; ${ }^{6}$ Engo-Agroo., Dr., Prof., Dep. de Ciências Agronômicas e Ambientais, UFSM/Cesnors, <claudirbasso@gmail.com>; ${ }^{7}$ Engo-Agrō., Dr., Prof., Departamento de Ciências Agronômicas e Ambientais, UFSM/Cesnors, <santi_pratica@yahoo.com.br>.

Planta Daninha, Viçosa-MG, v. 31, n. 3, p. 521-531, 2013 


\section{INTRODUÇÃO}

O trigo ocupa o primeiro lugar em volume de produção mundial, destacando-se como maiores produtores China, Estados Unidos, Índia, Canadá e Rússia (Embrapa, 2011). O Brasil possui uma demanda anual que gira em torno de 10 milhões de toneladas, produzindo o equivalente a 5 milhões de tonelada ano $^{-1}$, ou seja, a metade, e, portanto, importando a quantidade restante (Embrapa, 2011). Entre os fatores que limitam a expressão do potencial produtivo da cultura do trigo está a competição com as plantas daninhas, as quais disputam luz, nutrientes e água com a cultura, trazendo prejuízos em volume e qualidade do trigo produzido por área.

A competição com as plantas infestantes causa grandes perdas em produtividade ao trigo, gerando aumento nos custos de produção com a utilização de herbicidas, o que torna a cultura cada vez menos atraente economicamente. Por ser cultivado em diversas regiões brasileiras, várias espécies daninhas ocasionam perdas econômicas para o trigo. $\mathrm{Na}$ região Sul, as espécies Liliopsida - azevém (Lolium multiflorum) e Magnoliopsida - nabo (Raphanus spp.) destacam-se como as principais plantas daninhas infestantes da cultura, tendo sua incidência aumentada nos últimos anos devido à utilização como cobertura de solo e formação de pastagens de inverno.

Para o controle das espécies daninhas em lavouras tritícolas, dispõe-se de alguns herbicidas até então eficientes e seletivos. Todavia, o uso repetitivo deles tem selecionado espécies daninhas resistentes mundialmente, como é o caso de nabo resistente a herbicidas inibidores da enzima acetolactato sintase (ALS) e do azevém resistente ao herbicida glyphosate e à ALS (Heap, 2012). O surgimento de plantas daninhas resistentes nas lavouras dificulta o manejo, onerando muitas vezes os custos de produção, devido à necessidade de uso de herbicidas alternativos com preço superior.

O conhecimento de características morfológicas das plantas cultivadas, as quais sejam vantajosas na competição com plantas infestantes, é de suma importância para que o produtor as utilize como uma ferramenta no manejo integrado de plantas daninhas. Desse modo, é possivel explorar a habilidade competitiva da cultura e reduzir a dependência do controle químico. De acordo com Lemerle et al. (2001), cultivares de trigo com elevada habilidade competitiva com as plantas daninhas apresentam características como estatura de planta superior, folhas largas e decumbentes, crescimento vigoroso, boa capacidade de afilhamento e cobertura do solo.

A estatura de planta superior juntamente com adequada área foliar pela planta cultivada podem influenciar a habilidade competitiva desta com as plantas daninhas, reduzindo a penetração da luz no dossel e refletindo em menores perdas na produtividade de grãos (Duarte et al., 2002). De acordo com Rigoli et al. (2009), os cultivares de trigo BRS Guatambu e BRS Timbaúva, de ciclos longo e médio, respectivamente, e alta estatura de planta, destacaram-se quando em períodos de convivência com plantas de nabo e azevém, apresentando maior potencial competitivo no início do ciclo.

A época e a duração do período de convivência entre plantas daninhas e cultura influenciam a intensidade da competição; no início do ciclo de desenvolvimento, a cultura e a comunidade infestante podem conviver por determinado período sem que ocorram efeitos danosos sobre a produtividade da espécie cultivada (Brighenti et al., 2004). Contudo, plantas com elevada velocidade de emergência e de crescimento inicial possuem prioridade na utilização dos recursos do meio e, por isso, levam vantagem na utilização destes (Gustafson et al., 2004), ocupando primeiramente o nicho ecológico.

Objetivou-se com este trabalho avaliar o potencial de cultivares de trigo em competir com o azevém e o nabo em períodos de convivência.

\section{MATERIAL E MÉTODOS}

Foi realizado um experimento em campo, no município de Frederico Westphalen-RS, em 2010. O solo da área experimental é classificado como Latossolo Vermelho (Embrapa, 2006). Os cultivares de trigo foram semeados em 19/6/2010, com espaçamento de 0,17 m 
entre linhas, visando a população de plantas de 350 plantas $\mathrm{m}^{-2}$. As unidades experimentais apresentavam dimensões de $1,5 \times 1,0 \mathrm{~m}$ $\left(1,5 \mathrm{~m}^{2}\right)$. A adubação foi feita com base na CQFSRS/SC (2004), sendo aplicados $250 \mathrm{~kg} \mathrm{ha}^{-1}$ da fórmula 5-20-20 (N-P-K) e $135 \mathrm{~kg} \mathrm{ha}^{-1}$ de N na forma de ureia em cobertura, divididos entre os estádios de afilhamento e o emborrachamento da cultura.

As parcelas foram infestadas com sementes de azevém e nabo, objetivando estabelecer populações de 24 e 28 plantas $\mathrm{m}^{-2}$, respectivamente. A semeadura foi realizada com uma margem de folga, para que, quando das contagens visando verificar as populações de plantas daninhas, fossem realizados desbastes, se necessário. As demais plantas daninhas ocorrentes foram controladas manualmente. O delineamento experimental foi o de blocos ao acaso, arranjado em esquema fatorial $4 \times 2 \times 3$, com três repetições. No fator A alocaram-se os cultivares de trigo (BRS Guamirim - ciclo precoce e estatura baixa; Fundacep Cristalino - ciclo precoce e estatura média; Fundacep Raízes - ciclo médio e estatura média; e BRS 296 - ciclo precoce e estatura alta); no B, ausência ou presença de controle das espécies daninhas; e no $\mathrm{C}$, a época de manejo das espécies daninhas (durante todo o ciclo da cultura ou até a colheita, até 15 dias após a semeadura e até 30 dias após a semeadura).

O potencial de afilhamento foi avaliado através da contagem do número de afilhos por planta, em dez plantas aleatórias por parcela, no estádio de pré-alongamento do trigo. Também em dez plantas por parcela, avaliouse a estatura de plantas ao final de cada fase de convivência com as plantas daninhas.

A incidência de plantas daninhas (azevém e nabo) nos tratamentos foi verificada pela contagem do número de plantas por metro quadrado, no final de cada período de convivência; coletou-se a parte aérea para determinação da massa seca delas, acondicionando-as em sacos de papel e secando em estufa a $60{ }^{\circ} \mathrm{C}$, até se obter massa constante. O estádio de desenvolvimento do trigo foi determinado visualmente pela escala proposta por Haun (1973), sendo eles: 1 (emergência das plântulas), 2 (emborrachamento), 3 (floração) e 4 (maturação fisiológica).
O potencial competitivo dos cultivares foi estimado por meio de avaliação visual realizada a partir do primeiro nó visível no colmo principal do trigo, de acordo com Lemerle et al. (2001). Foram atribuídas as notas por três avaliadores, equivalentes a 1,3 ou 5 , aos cultivares que apresentaram características como baixo, médio ou alto potencial competitivo, respectivamente, utilizando-se características como estatura de planta, largura e inclinação das folhas, bem como afilhamento, como base.

A colheita foi feita em 24/11/2010, em área útil de $1 \mathrm{~m}^{2}$, quando foram determinados os componentes da produtividade: número de colmos por metro quadrado, número de espigas por metro quadrado e número de grãos por espiga. Esta última variável foi determinada através da média da contagem dos grãos de cinco plantas, colhidas aleatoriamente nas unidades experimentais. O peso de mil grãos foi determinado pela contagem de oito repetições de 100 subamostras de sementes, pesadas em balança analítica de precisão, sendo os resultados expressos em gramas, de acordo com as Regras para Análise de Sementes - RAS (Brasil, 2009). A produtividade de grãos foi determinada corrigindo-se o teor de umidade para $13 \%$, e os dados, convertidos para $\mathrm{kg} \mathrm{ha} \mathrm{h}^{-1}$. Os dados obtidos foram submetidos à análise de variância e, havendo significância, os tratamentos foram comparados pelo teste de Duncan a 5\% de probabilidade.

\section{RESULTADOS E DISCUSSÃO}

Houve interação para o número de afilhos por planta dos cultivares de trigo, para os fatores ausência ou presença de controle das plantas daninhas e épocas (Tabela 1). Não foi observada, na média, diferença no número de afilhos por planta quando os cultivares conviveram com as espécies daninhas até 15 e 30 DAS. Entretanto, quando o manejo das infestantes não foi realizado até a colheita, o número de afilhos por planta foi reduzido em cerca de $20 \%$, quando comparado ao mesmo período com controle das espécies daninhas (Tabela 1).

Agostinetto et al. (2008) observaram que a infestação de plantas de nabo e azevém fez com que o trigo acumulasse menos matéria seca no período de convivência, 
Tabela 1 - Número de afilhos por planta de cultivares de trigo, em função do controle ou da convivência com plantas daninhas até 15, 30 dias após a semeadura (DAS) e colheita. Frederico Westphalen-RS, 2010

\begin{tabular}{|c|c|c|c|}
\hline \multirow{3}{*}{ Tratamento } & \multicolumn{3}{|c|}{ Época } \\
\hline & $15 \mathrm{DAS}^{1 /}$ & $30 \mathrm{DAS}$ & Pré-colheita \\
\hline & \multicolumn{3}{|c|}{ Número de afilhos por planta } \\
\hline Controle & $1,50 \mathrm{~A}^{2 /}$ & $1,72 \mathrm{~A}$ & $1,44 \mathrm{~A}$ \\
\hline Ausência de controle & $1,81 \mathrm{~A}$ & $1,68 \mathrm{~A}$ & $1,11 \mathrm{~B}$ \\
\hline CV $(\%)$ & \multicolumn{3}{|c|}{25,67} \\
\hline
\end{tabular}

1/ Dias após a semeadura. ${ }^{2 /}$ Letras semelhantes nas colunas não diferem entre si pelo teste de Duncan a $5 \%$ de probabilidade.

possivelmente pela menor emissão e sobrevivência dos afilhos. Contudo, os cultivares de trigo apresentaram maior estatura de planta ainda no período de convivência com as infestantes, o que pode decorrer do fato de a conversão de assimilados ter sido revertida ao colmo principal.

A capacidade de afilhamento, em cultivares de trigo, é de extrema importância na definição da sua competitividade com as plantas daninhas (Hucl, 1997). Segundo Almeida $\&$ Mundstock (2001), a luz é determinante na capacidade de afilhamento e produtividade da cultura do trigo. Os cereais de inverno, quando em competição por luz, aumentam o investimento de fotoassimilados na formação de colmos mais longos, ou seja, ocorre estiolamento na tentativa de captar mais luminosidade, com menor investimento de energia para o afilhamento, desenvolvimento de área foliar e de massa seca e crescimento radicular; até mesmo a produtividade de grãos pode ser afetada, pois a planta investe mais energia no órgão que estiver com maior déficit nutricional, em contraponto aos demais (Galon et al., 2011).

Para a estatura de plantas em trigo, houve significância para os fatores cultivares e para o controle das plantas daninhas ou ausência deste, conforme as Tabelas 2 e 3 . Não foi observada diferença, na média, entre os cultivares de trigo para a estatura nos períodos de 15 e 30 DAS (Tabela 2). Quando da colheita, Fundacep Raízes apresentou estatura de planta superior, em média, $83,68 \mathrm{~cm}$, enquanto BRS Guamirim apresentou a menor estatura, equivalente a $73,35 \mathrm{~cm}$. De acordo com
Fleck et al. (2007), plantas detentoras de características como estatura e índice de área foliar elevados identificam culturas com bom potencial competitivo com as plantas daninhas. Cultivares de trigo com elevada habilidade competitiva com plantas daninhas apresentaram características como estatura elevada, folhas largas e decumbentes, crescimento vigoroso, abundante afilhamento e elevada cobertura do solo (Lemerle et al., 2001).

A estatura de plantas dos cultivares de trigo no final de cada período de convivência demonstrou comportamentos distintos. Nos períodos de manejo até 15 DAS e até a colheita, as plantas de trigo apresentaram, de maneira geral, as estaturas de planta mais elevadas quando comparadas às dos mesmos períodos sem controle das infestantes (Tabela 3). Todavia, no período de controle até 30 DAS, não houve diferença entre os tratamentos com ou

Tabela 2 - Estatura de planta de cultivares de trigo, em função do controle ou da convivência com plantas daninhas até 15, 30 dias após a semeadura (DAS) e colheita. Frederico Westphalen-RS, 2011

\begin{tabular}{|l|c|c|l|}
\hline \multirow{2}{*}{\multicolumn{1}{|c|}{ Cultivar }} & \multicolumn{3}{|c|}{ Época } \\
\cline { 2 - 4 } & $15 \mathrm{DAS}^{1 /}$ & $30 \mathrm{DAS}$ & Pré-colheita \\
\cline { 2 - 4 } & \multicolumn{3}{|c|}{ Estatura (cm) } \\
\hline Fundacep Raízes & $6,95 \mathrm{~A}^{2 /}$ & $14,30 \mathrm{~A}$ & $83,68 \mathrm{~A}$ \\
\hline BRS 296 & $7,09 \mathrm{~A}$ & $13,36 \mathrm{~A}$ & $78,53 \mathrm{AB}$ \\
\hline BRS Guamirim & $7,29 \mathrm{~A}$ & $13,47 \mathrm{~A}$ & $73,35 \mathrm{~B}$ \\
\hline Fundacep Cristalino & $6,96 \mathrm{~A}$ & $13,91 \mathrm{~A}$ & $81,77 \mathrm{AB}$ \\
\hline \multicolumn{1}{|c|}{ CV $(\%)$} & 4,18 & 5,56 & 8,36 \\
\hline
\end{tabular}

${ }^{1 /}$ Dias após a semeadura. ${ }^{2 /}$ Letras semelhantes nas colunas não diferem entre si pelo teste de Duncan a $5 \%$ de probabilidade.

Tabela 3 - Estatura de planta de cultivares de trigo, em função do controle ou da convivência com plantas daninhas até 15, 30 dias após a semeadura (DAS) e colheita. Frederico Westphalen-RS, 2011

\begin{tabular}{|c|c|c|c|}
\hline \multirow{3}{*}{ Tratamento } & \multicolumn{3}{|c|}{ Época } \\
\hline & $15 \mathrm{DAS}^{1 /}$ & $30 \mathrm{DAS}$ & Pré-colheita \\
\hline & \multicolumn{3}{|c|}{ Estatura $(\mathrm{cm})$} \\
\hline Controle & $7,21 \mathrm{~A}^{2 /}$ & $13,79 \mathrm{~A}$ & $83,58 \mathrm{~A}$ \\
\hline Ausência de controle & $6,94 \mathrm{~B}$ & $13,72 \mathrm{~A}$ & $75,08 \mathrm{~B}$ \\
\hline $\mathrm{CV}(\%)$ & 4,18 & 5,56 & 8,36 \\
\hline
\end{tabular}

1/ Dias após a semeadura. ${ }^{2 /}$ Letras semelhantes nas colunas não diferem entre si pelo teste de Duncan a $5 \%$ de probabilidade. 
sem controle das espécies daninhas. Segundo Rigoli et al. (2009), a maior área foliar de cultivares de trigo, juntamente com a estatura elevada, proporcionaria a formação de um dossel denso, que, em campo, conduziria a uma adequada cobertura do solo e reduziria a penetração de luz no dossel da comunidade e, consequentemente, levaria à não ocorrência de plantas daninhas.

Em experimento realizado por Rigoli et al. (2009), cultivares de trigo demonstraram, para a variável estatura de planta, em geral, maiores estaturas aos 10, 20 e 35 dias após a emergência (DAE). No presente estudo, na média, quando houve controle das infestantes, a estatura de planta do trigo foi de $83,58 \mathrm{~cm}$, $10 \%$ superior, quando, na média, na ausência de controle, equivaleu a 75,08 $\mathrm{cm}$ (Tabela 3). Plantas altas, em geral, demonstram maior competitividade com infestantes, devido à vantagem obtida na captação de radiação solar em relação a espécies daninhas mais baixas, conforme verificado em trigo.

Analisando-se o número de colmos por metro quadrado dos cultivares de trigo, houve interação significativa entre os fatores. Em função do controle das plantas daninhas até 15 DAS, verifica-se que não há diferença significativa entre os cultivares (Tabela 4). Entretanto, até 30 DAS e até a colheita percebeuse desempenho superior do cultivar BRS Guamirim perante os demais para a variável em questão. Comparando os períodos de competição para cada cultivar, observa-se que não houve diferença entre eles.

Para o tratamento com ausência de controle das plantas daninhas até 15 DAS, o número de colmos por metro quadrado foi superior (cerca de 30\%) para BRS Guamirim e Fundacep Raízes, quando comparado ao dos demais cultivares (Tabela 4). Nos períodos de competição até 30 DAS e colheita, não houve diferença entre os cultivares avaliados.

Comparando cada cultivar em função dos periodos de convivência sem controle de plantas daninhas, verifica-se que para BRS 296 e Fundacep Cristalino o número de colmos até 15, 30 DAS e colheita não apresentou diferença (Tabela 4). Contudo, para BRS Guamirim observou-se redução no número de colmos quando não houve manejo das infestantes até a colheita, cerca de $30 \%$, quando comparado ao período sem controle até 15 DAS. Para o cultivar Fundacep Raizes, observou-se melhor desempenho quando o manejo das infestantes foi realizado até $30 \mathrm{DAS}$, apresentando 287,25 colmos por metro quadrado, em torno de $20 \%$ a mais que no período sem controle até a pré-colheita. Esse resultado ressalta a importância do manejo precoce das espécies infestantes, visando evitar o comprometimento do desenvolvimento da cultura.

Em estudo com trigo, Agostinetto et al. (2008) não verificaram diferenças, analisando

Tabela 4 - Número de colmos por metro quadrado de cultivares de trigo, em função do controle ou da convivência com plantas daninhas até 15, 30 dias após a semeadura (DAS) e colheita. Frederico Westphalen-RS, 2010

\begin{tabular}{|c|c|c|c|c|c|c|}
\hline \multirow{3}{*}{ Cultivar } & \multicolumn{3}{|c|}{ Controle } & \multicolumn{3}{|c|}{ Ausência de controle } \\
\hline & $15 \mathrm{DAS}^{1 /}$ & 30 DAS & Colheita & 15 DAS & 30 DAS & Colheita \\
\hline & \multicolumn{6}{|c|}{ Número de colmos por metro quadrado } \\
\hline Fundacep Raízes & $\mathrm{A}^{2 / 2} 244,12 \mathrm{a}^{\underline{2} /}$ & $\mathrm{AB} 232,35 \mathrm{a}$ & $\mathrm{AB} 271,57 \mathrm{a}$ & A $279,41 \mathrm{ab}$ & A 287,25 a & A $220,59 b$ \\
\hline BRS 296 & A 228,43 a & $\mathrm{AB} 268,63 \mathrm{a}$ & B 214,71 a & B 202,94 a & A 232,35 a & A $226,47 \mathrm{a}$ \\
\hline BRS Guamirim & A 266,67 a & A 282,35 a & A 320,59 a & A 283,33 a & A $263,72 \mathrm{a}$ & A 189,22 b \\
\hline Fundacep Cristalino & A 216,67 a & B $219,61 \mathrm{a}$ & B $237,25 \mathrm{a}$ & B $200,00 \mathrm{a}$ & A 247,06 a & A 232,35 a \\
\hline CV (\%) & \multicolumn{6}{|c|}{18,48} \\
\hline
\end{tabular}


períodos de controle ou convivência, para as variáveis estatura de planta e número de colmos por área nos períodos de controle, determinadas no final do ciclo. Já para número de colmos por área nos períodos de convivência, constataram-se diferenças somente para convivência durante todo o ciclo da cultura, em relação aos períodos iniciais. Ainda de acordo com os mesmos autores, isso ocorre pelo fato de a competição do trigo com as plantas daninhas até o final do ciclo ter sido mais intensa e, consequentemente, formouse menor números de afilhos e de colmos. Portanto, para ambas as variáveis, não se verificaram diferenças entre períodos de controle ou de convivência.

Quanto ao número de espigas por metro quadrado, observou-se interação significativa entre todos os fatores analisados. Nos tratamentos com controle das plantas daninhas até 15, 30 DAS e colheita não se observou diferença entre os cultivares (Tabela 5). No entanto, analisando o comportamento de cada cultivar nos períodos de convivência, verificou-se que, no geral, para todos eles, controlando as infestantes até a colheita, obtém-se maior número de espigas $\mathrm{m}^{-2}$, contrariamente ao observado quando o controle foi realizado somente até 15 DAS, quando foram verificados os menores valores para a variável.

No período com ausência de controle até 15 DAS, o cultivar BRS Guamirim demonstrou-se superior aos demais, produzindo 270,59 espigas $\mathrm{m}^{-2}$, cerca de $30 \%$ a mais que
Fundacep Cristalino. No período de ausência de controle durante todo o ciclo, Fundacep Raízes apresentou desempenho inferior ao dos demais cultivares, produzindo em torno de $45 \%$ a menos que BRS 296 (Tabela 5). Na ausência de controle das infestantes até 30 DAS, não se observou diferença significativa entre os cultivares (Tabela 5).

Na comparação dos períodos de convivência com ausência de controle, observou-se que os cultivares BRS 296 e Cristalino não demonstraram diferença entre as épocas de competição (Tabela 5). Contudo, BRS Guamirim e Fundacep Raízes manifestaram decréscimo no número de espigas na convivência com as daninhas até a colheita, apresentando 123,53 e 102,94 espigas $\mathrm{m}^{-2}$, respectivamente, cerca de $50 \%$ a menos, comparando-se ao período de convivência até ou ausência de controle até 15 DAS.

A habilidade competitiva de uma planta refere-se à capacidade de ela suprimir o crescimento de outra ou à sua habilidade em manter relativamente inalterado seu crescimento na presença de competidores, evitando desse modo ser suprimida (Goldberg \& Landa, 1991). Analisando-se o efeito dos cultivares de trigo sobre as espécies daninhas, na ausência de controle até 15 DAS, não foram observadas diferenças (dados não mostrados). Já aos 30 DAS sem controle das espécies daninhas, a produção de massa pelo azevém foi equivalente a $1,6 \mathrm{~kg} \mathrm{ha}^{-1}$ quando na convivência de BRS Guamirim. Quando na presença de

Tabela 5 - Número de espigas por metro quadrado de cultivares de trigo em função do controle ou da convivência com plantas daninhas até 15, 30 dias após a semeadura (DAS) e colheita. Frederico Westphalen-RS, 2010

\begin{tabular}{|c|c|c|c|c|c|c|}
\hline \multirow{3}{*}{ Cultivar } & \multicolumn{3}{|c|}{ Controle } & \multicolumn{3}{|c|}{ Ausência de controle } \\
\hline & $15 \mathrm{DAS}^{1 /}$ & $30 \mathrm{DAS}$ & Colheita & $15 \mathrm{DAS}$ & 30 DAS & Colheita \\
\hline & \multicolumn{6}{|c|}{ Número de espigas por metro quadrado } \\
\hline Fundacep Raízes & $\mathrm{A}^{\underline{2} /} 180,88 \mathrm{~b}^{2 /}$ & A 205,69 b & $\mathrm{A} 273,53 \mathrm{a}$ & B $208,82 \mathrm{a}$ & A $231,37 \mathrm{a}$ & B $102,94 \mathrm{~b}$ \\
\hline BRS 296 & A $182,35 \mathrm{~b}$ & A $231,37 \mathrm{ab}$ & A 247,06 a & B $189,22 \mathrm{a}$ & A $212,74 \mathrm{a}$ & A 193,14 a \\
\hline BRS Guamirim & A $207,84 \mathrm{~b}$ & A $251,96 \mathrm{ab}$ & A 296,08 a & A $270,59 \mathrm{a}$ & A 242,16 a & AB $123,53 b$ \\
\hline Fundacep Cristalino & A 194,12 b & A $207,84 \mathrm{ab}$ & A 266,67 a & B 185,29 a & A 227,45 a & A1 72,06 a \\
\hline $\mathrm{CV}(\%)$ & \multicolumn{6}{|c|}{17,49} \\
\hline
\end{tabular}

${ }_{1 /}$ Dias após a semeadura. ${ }^{2}$ Letras semelhantes nas colunas (maiúsculas) e nas linhas (minúsculas) não diferem entre si pelo teste de Duncan a $5 \%$ de probabilidade. 
Fundacep Cristalino, a massa seca produzida pela infestante equivaleu a $0,4 \mathrm{~kg} \mathrm{ha}^{-1}$ (dados não mostrados). Isso demonstra o efeito supressivo superior do Fundacep Cristalino, cultivar de estatura elevada, sobre o azevém, quando comparado ao BRS Guamirim, cultivar de estatura baixa.

Em ensaios com arroz irrigado por inundação, Ni et al. (2000) determinaram que a velocidade de acúmulo de massa na parte aérea pela cultura até o início do afilhamento (cerca de 35 DAS do arroz) foi a variável mais importante na predição do acúmulo de massa pelas plantas daninhas presentes na área de cultivo. Essa variável correlacionou-se com a formação de dossel com elevado potencial de captação de energia radiante, reduzindo a disponibilidade desse recurso às infestantes.

No período total de convivência com os cultivares, ou seja, até a colheita, a massa seca da parte aérea do azevém foi suprimida pelo cultivar BRS 296, quando comparada com a dos demais cultivares (Tabela 6). Já para o nabo, a convivência com Fundacep Cristalino e Fundacep Raízes proporcionou a obtenção de menores valores de massa seca da parte aérea, comparando aos demais cultivares (Tabela 6). Esses resultados ressaltam a capacidade do trigo de suprimir o desenvolvimento da espécie daninha, o que pode variar conforme caracteristicas intrínsecas de cada cultivar.

Na determinação dos estádios de desenvolvimento da cultura do trigo, pode-se verificar que todos os cultivares emergiram no mesmo período, porém, no decorrer do seu ciclo, cada um expressou suas características distintas (Tabela 7). Os cultivares Fundacep Raízes e Cristalino atingiram a maturação fisiológica primeiramente, seguidos por BRS Guamirim. BRS 296 foi o cultivar que apresentou ciclo mais tardio, entre os cultivares avaliados.

$\mathrm{Na}$ avaliação do potencial competitivo do trigo, observou-se que os cultivares respondem de maneira diferenciada à competição com as espécies daninhas. Fundacep Raízes e Fundacep Cristalino apresentaram desempenho superior ao dos demais cultivares, exibindo potenciais competitivos da ordem de 4,78 e 4,11, respectivamente (dados não mostrados). Esses valores aproximam-se de 5, valor que, pela escala utilizada (Lemerle et al., 2001), equivale a cultivar com alta capacidade competitiva.

Para a variável número de grãos por espiga, o controle das infestantes até 15 DAS e colheita resultou em maiores valores para Fundacep Raízes, com 32,9 e 38,9 grãos por espiga, respectivamente para cada período. BRS 296 apresentou redução de 55\% no número de grãos por espiga quando comparado ao Fundacep Raízes (Tabela 8), no período até 15 DAS. Quando do controle até a pré-colheita, BRS Guamirim demonstrou resultado inferior, com cerca de $30 \%$ de redução no número de grãos por espiga, quando comparado ao Fundacep Raízes. No período de convivência até 30 DAS, não se verificou diferença entre os cultivares.

Quando da convivência com as infestantes ou ausência de controle até 15 DAS, o cultivar BRS 296 demonstrou redução de 50\% no número de grãos por espiga, comparando-se ao período de até 30 DAS (Tabela 8). Os demais cultivares não apresentaram diferenças entre as épocas.

No tratamento sem controle das plantas daninhas até 15 e 30 DAS, o cultivar BRS Guamirim mostrou redução de cerca de 40 e $50 \%$, respectivamente, no número de grão por espiga, quando comparada à de Fundacep Raízes. Quando da ausência de manejo até a colheita, Fundacep Cristalino apresentou o melhor desempenho, com 19,4 grãos por espiga, superior em quase $50 \%$ aos resultados de BRS Guamirim (Tabela 8). Comparando os períodos de competição, observou-se que todos os cultivares demonstraram decréscimo no número de grãos por espiga quando da convivência durante todo o ciclo com as plantas daninhas.

O peso de mil grãos, em função do controle ou da convivência com as plantas daninhas até 15 e 30 DAS, não diferiu (Tabela 9). Entretanto, quando não houve o controle das espécies daninhas até a colheita, o peso de mil grãos foi $15 \%$ menor, quando comparado ao mesmo período, porém com controle das espécies daninhas. De acordo com trabalho realizado por Duarte et al. (2002), o peso de grãos não se alterou quando a capina da cultura do milho foi realizada somente até o 
Tabela 6 - Massa seca $\left(\mathrm{kg} \mathrm{ha}^{-1}\right)$ da parte aérea de azevém e nabo, em função do controle ou ausência deste, em convivência com cultivares de trigo, na colheita. Frederico Westphalen-RS, 2010

\begin{tabular}{|c|c|c|c|c|}
\hline \multirow{3}{*}{ Cultivar } & \multicolumn{2}{|c|}{ Azevém } & \multicolumn{2}{|c|}{ Nabo } \\
\hline & Com controle & Sem controle & Com controle & Sem controle \\
\hline & \multicolumn{4}{|c|}{ Massa seca $\left(\mathrm{kg} \mathrm{ha}^{-1}\right)$} \\
\hline Fundacep Raízes & $0,00 \mathrm{~A}^{1 /}$ & $245,73 \mathrm{~A}$ & $0,00 \mathrm{~A}$ & $3755,87 \mathrm{~B}$ \\
\hline BRS 296 & $0,00 \mathrm{~A}$ & $141,00 \mathrm{~B}$ & $0,00 \mathrm{~A}$ & $5911,47 \mathrm{~A}$ \\
\hline BRS Guamirim & $0,00 \mathrm{~A}$ & $291,73 \mathrm{~A}$ & $0,00 \mathrm{~A}$ & $6758,93 \mathrm{~A}$ \\
\hline Fundacep Cristalino & $0,00 \mathrm{~A}$ & $279,33 \mathrm{~A}$ & $0,00 \mathrm{~A}$ & $4514,27 \mathrm{~B}$ \\
\hline CV $(\%)$ & \multicolumn{2}{|c|}{17,6} & \multicolumn{2}{|c|}{7,16} \\
\hline
\end{tabular}

1/ Letras maiúsculas semelhantes nas colunas não diferem entre si pelo teste de Duncan a 5\% de probabilidade.

Tabela 7 - Estádios de desenvolvimento de cultivares de trigo. Frederico Westphalen-RS, 2010

\begin{tabular}{|l|c|c|c|c|}
\hline \multirow{2}{*}{\multicolumn{1}{c|}{ Cultivar }} & \multicolumn{4}{c|}{ Estádio de desenvolvimento do trigo } \\
\cline { 2 - 5 } & Emergência $^{\underline{1}}$ & Emborrachamento & Floração & Maturação fisiológica \\
\hline Fundacep Raízes & 27 de junho & 27 de agosto & 15 de setembro & 20 de outubro \\
\hline BRS 296 & 27 de junho & 10 de setembro & 25 de setembro & 29 de outubro \\
\hline Fundacep Cristalino & 27 de junho & 04 de setembro & 15 de setembro & 20 de outubro \\
\hline BRS Guamirim & 27 de junho & 22 de agosto & 18 de setembro & 25 de outubro \\
\hline
\end{tabular}

1/ Baseado na escala Haun (1973).

Tabela 8 - Número de grãos por espiga de cultivares de trigo, em função do controle ou da convivência com plantas daninhas até 15 , 30 dias após a semeadura e colheita. Frederico Westphalen-RS, 2010

\begin{tabular}{|c|c|c|c|c|c|c|}
\hline \multirow{3}{*}{ Cultivar } & \multicolumn{3}{|c|}{ Controle } & \multicolumn{3}{|c|}{ Ausência de controle } \\
\hline & $15 \mathrm{DAS}^{1 /}$ & 30 DAS & Colheita & 15 DAS & 30 DAS & Colheita \\
\hline & \multicolumn{6}{|c|}{ Número de grãos por espiga } \\
\hline Fundacep Raízes & 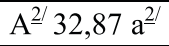 & A 31,40 a & A $38,90 \mathrm{a}$ & A $37,40 \mathrm{a}$ & A 37,07 a & $\mathrm{AB} 14,33 \mathrm{~b}$ \\
\hline BRS 296 & $\mathrm{C} 14,80 \mathrm{~b}$ & A 30,13 a & B 29,13 a & A $32,00 \mathrm{a}$ & $\mathrm{BC} 26,13 \mathrm{a}$ & B $11,27 \mathrm{~b}$ \\
\hline BRS Guamirim & B 24,07 a & A 25,93 a & B $26,20 \mathrm{a}$ & B $23,07 \mathrm{a}$ & C $18,93 \mathrm{a}$ & B $10,00 \mathrm{~b}$ \\
\hline Fundacep Cristalino & AB 29,47 a & A 29,07 a & AB 34,20 a & $\mathrm{AB} 30,47 \mathrm{a}$ & $\mathrm{AB} 31,87 \mathrm{a}$ & A $19,40 \mathrm{~b}$ \\
\hline $\mathrm{CV}(\%)$ & \multicolumn{6}{|c|}{15,26} \\
\hline
\end{tabular}

${ }^{1 /}$ Dias após a semeadura. ${ }^{2 /}$ Letras semelhantes nas colunas (maiúsculas) e nas linhas (minúsculas) não diferem entre si pelo teste de Duncan a $5 \%$ de probabilidade.

pendoamento, em comparação com a eliminação total das plantas daninhas durante todo o ciclo da cultura.

$\mathrm{Na}$ avaliação da produtividade, houve interação entre todos os fatores. Os cultivares de trigo mostraram respostas diferenciadas de acordo com o período em que a cultura se manteve na presença ou na ausência de competição com as plantas daninhas. No tratamento-padrão, no qual a cultura foi mantida no limpo durante todo o ciclo, todos os cultivares demonstraram elevadas produtividades;
Fundacep Raízes mostrou o melhor desempenho, produzindo $6878,9 \mathrm{~kg} \mathrm{ha}^{-1}$, enquanto BRS Guamirim, embora ainda com elevada produtividade, apresentou o menor valor equivalente a $5476,4 \mathrm{~kg} \mathrm{ha}^{-1}$ (Tabela 10).

Quando o controle das espécies daninhas foi feito até os 15 DAS e posteriormente não se realizou nenhum método de manejo, a produtividade de Fundacep Cristalino e de Fundacep Raízes reduziu em 14 e 17\%, respectivamente. Já para BRS Guamirim e BRS 296, o efeito no rendimento de grãos foi 
aproximadamente $40 \%$ inferior quando o manejo de daninhas foi realizado somente até 15 DAS. Esses resultados reforçam aqueles observados por Agostinetto et al. (2008), que indicam um periodo entre 12 e $24 \mathrm{DAE}$ para o desenvolvimento da cultura do trigo no limpo, visando evitar maiores perdas de produtividade pela presença de plantas competidoras. Quando o controle das plantas daninhas foi realizado até os 30 DAS, somente os cultivares BRS 296 e Raízes tiveram redução significativa de aproximadamente $20 \%$ em suas produtividades (Tabela 10). As plantas daninhas alteram significativamente a produtividade de grãos de cevada, podendo comprometer, além do rendimento de grãos, a qualidade da matéria-prima destinada à indústria (Galon et al., 2011).

A convivência com o azevém e o nabo durante todo o ciclo dos cultivares causou reduções severas no rendimento de grãos. Nesse caso, BRS Guamirim e Fundacep Raízes produziram o equivalente a 844,5 e $842,5 \mathrm{~kg} \mathrm{ha}^{-1}$, respectivamente, ou seja, 80 e $85 \%$ a menos quando comparada a convivência com as infestantes até 30 DAS. Entretanto, o cultivar Fundacep Cristalino teve redução de apenas $40 \%$ na produção nos mesmos períodos de convivência analisados. A presença das plantas daninhas até esta época (30 DAS) foi mais prejudicial a BRS Guamirim quando comparado a Fundacep Cristalino, enquanto os demais não diferiram estatisticamente de ambos.
O cultivar Fundacep Cristalino, com ciclo precoce e estatura média, demonstrou elevada produtividade em todos os períodos de convivência ou ausência de competição, destacando sua superioridade quando na ausência de controle durante todo o ciclo da cultura. Embora BRS Guamirim também seja um cultivar precoce, com rápido estabelecimento e bom vigor inicial, e bastante difundido na região norte do RS, sua baixa estatura de planta, quando comparado a Fundacep Cristalino, pode ter sido responsável pela menor habilidade deste em competir com as plantas daninhas nos estádios iniciais avaliados.

De acordo com Blackshaw (1994), em trigo a estatura de planta revelou-se uma característica associada ao incremento na

Tabela 9 - Peso de mil grãos (g) de cultivares de trigo, em função do controle ou da convivência com plantas daninhas até 15, 30 dias após a semeadura e colheita. Frederico Westphalen-RS, 2010

\begin{tabular}{|c|c|c|c|}
\hline \multirow{3}{*}{ Tratamento } & \multicolumn{3}{|c|}{ Época } \\
\hline & $15 \mathrm{DAS}^{1 /}$ & 30 DAS & Colheita \\
\hline & \multicolumn{3}{|c|}{ Peso de mil grãos $(\mathrm{g})$} \\
\hline Controle & $30,12 \mathrm{~A}^{2 /}$ & $30,62 \mathrm{~A}$ & $31,32 \mathrm{~A}$ \\
\hline Ausência de controle & $31,48 \mathrm{~A}$ & $31,21 \mathrm{~A}$ & $26,66 \mathrm{~B}$ \\
\hline $\mathrm{CV}(\%)$ & \multicolumn{3}{|c|}{7,93} \\
\hline
\end{tabular}

1/ Dias após a semeadura. ${ }^{2 /}$ Letras maiúsculas semelhantes nas colunas não diferem entre si pelo teste de Duncan a $5 \%$ de probabilidade.

Tabela 10 - Produtividade de grãos $\left(\mathrm{kg} \mathrm{ha}^{-1}\right)$ de cultivares de trigo, em função do controle ou da convivência com plantas daninhas até 15, 30 dias após a semeadura e colheita. Frederico Westphalen-RS, 2010

\begin{tabular}{|c|c|c|c|c|c|c|}
\hline \multirow{3}{*}{ Cultivar } & \multicolumn{3}{|c|}{ Controle } & \multicolumn{3}{|c|}{ Ausência de controle } \\
\hline & $15 \mathrm{DAS}^{1 /}$ & $30 \mathrm{DAS}$ & Colheita & 15 DAS & 30 DAS & Colheita \\
\hline & \multicolumn{6}{|c|}{ Produtividade $\left(\mathrm{kg} \mathrm{ha}^{-1}\right)$} \\
\hline Fundacep Raízes & $\mathrm{A}^{2 /} 5722,60 \mathrm{ab}^{2 /}$ & $\mathrm{AB} 5492,60 \mathrm{~b}$ & A $6878,90 \mathrm{a}$ & A $5959,20 \mathrm{a}$ & AB 5399,90 a & B $842,50 \mathrm{~b}$ \\
\hline BRS 296 & B $3587,40 \mathrm{~b}$ & B $4576,60 \mathrm{ab}$ & $\mathrm{AB} 5826,30 \mathrm{a}$ & A 5724,60 a & $\mathrm{AB} 4820,80 \mathrm{a}$ & B $1432,50 \mathrm{~b}$ \\
\hline BRS Guamirim & B $3321,00 \mathrm{~b}$ & B 4729,70 a & B 5476,40 a & A 4687,70 a & B 4425,40 a & B $844,50 \mathrm{~b}$ \\
\hline Fundacep Cristalino & A $5645,20 \mathrm{a}$ & A 6277,60 a & $\mathrm{AB} 6579,70 \mathrm{a}$ & A $5325,60 \mathrm{a}$ & A $6065,90 \mathrm{a}$ & A $3426,60 \mathrm{~b}$ \\
\hline $\mathrm{CV}(\%)$ & \multicolumn{6}{|c|}{16,62} \\
\hline
\end{tabular}

1/ Dias após a semeadura. ${ }^{2 /}$ Letras semelhantes nas colunas (maiúsculas) e nas linhas (minúsculas) não diferem entre si pelo teste de Duncan a $5 \%$ de probabilidade. 
competitividade da cultura, juntamente com demais características de planta, como crescimento precoce, elevada capacidade de afilhamento e maior área foliar. O cultivar BRS 296, embora tenha apresentado estatura de planta mediana, o que pode favorecer seu potencial competitivo, foi o cultivar com ciclo mais tardio quando comparado aos demais. Os efeitos da interferência com as espécies daninhas são irreversiveis, não havendo recuperação do desenvolvimento ou da produtividade após a retirada do estresse causado pela presença das plantas daninhas (Kozlowski, 2002).

A diferença entre os cultivares ressalta a importância de manejar as plantas daninhas no momento indicado, ou seja, precocemente, visando evitar perdas e redução da expressão do potencial produtivo. De acordo com Rigoli et al. (2009), conhecer as características de desenvolvimento inicial de cultivares de trigo, a exemplo do que já ocorre com outras culturas anuais, é ferramenta importante no manejo integrado de plantas daninhas, visando aumentar a habilidade competitiva do cereal.

Vale ressaltar que a sustentabilidade da vantagem inicial dos cultivares é importante, pois, uma vez que as plantas daninhas que emergirem tardiamente ultrapassarem o dossel da cultura, sombreando-a, poderão comprometer o desenvolvimento e a produtividade do trigo. Portanto, mesmo utilizando-se da habilidade competitiva de cultivares, demais métodos de controle de plantas daninhas não devem ser abandonados ou esquecidos. Dessa maneira, observa-se que o estudo sobre a competitividade das culturas agrícolas com as espécies daninhas possibilita desenvolver estratégias para inserção em sistemas de manejo integrado, promovendo o uso racional de herbicidas, melhorando a eficiência de controle, minimizando os custos de produção, diminuindo os impactos ambientais e evitando o surgimento de plantas daninhas resistentes a herbicidas.

\section{AGRADECIMENTOS}

Ao CNPq e à Universidade Federal de Santa Maria-UFSM, pela concessão das bolsas de iniciação científica, PIBIC/CNPq e Fipe Jr/
UFSM. Aos colegas Girlei Bras de Souza e Marcos Piovesan Uliana, pelo auxílio na condução do experimento.

\section{LITERATURA CITADA}

AGOSTINETTO, D. et al. Período crítico de competição de plantas daninhas com a cultura do trigo. Planta Daninha, v. 26, n. 2 , p. $271-278,2008$

ALMEIDA, M. L.; MUNDSTOCK, C. M. A qualidade da luz afeta o afilhamento em plantas de trigo, quando cultivadas sob competição. Ci. Rural, v. 31, n. 3, p. 401-408, 2001.

BLACKSHAW, R. E. Differential competitive ability of winter wheat cultivars against downy brome. Agron. J., v. 86, n. 4, p. 649-654, 1994.

BRASIL. Ministério da Agricultura, Pecuária e Abastecimento. Secretaria de Defesa Agropecuária. Regras para análise de sementes. Brasília: 2009

BRIGHENTI, A. M. et al. Períodos de interferência de plantas daninhas na cultura do girassol. Planta Daninha, v. 22 , n. 2 , p. $251-257,2004$

CQFS-RS/SC. COMISSÃO DE QUÍMICA E FERTILIDADE DO SOLO - RS/SC. Manual de adubação e calagem para os Estados do Rio Grande do Sul e Santa Catarina. Porto Alegre: SBCS-NRS/EMBRAPA-CNPT, 2004, 400 p.

DUARTE, N. F. et al. Competição de plantas daninhas com a cultura do milho no município de Ijaci, MG. Ci. Agrotec., v. 26, n. 5 , p. $983-992,2002$.

EMPRESA BRASILEIRA DE PESQUISA AGROPECUÁRIA - EMBRAPA. Centro Nacional de Pesquisa de Solos. Sistema brasileiro de classificação de solos. 2.ed. Rio de Janeiro: 2006. 306 p.

EMPRESA BRASILEIRA DE PESQUISA

AGROPECUÁRIA - EMBRAPA. TRIGO. Disponível em: http://www.cnpt.embrapa.br/culturas/trig o/index.htm. Acesso em: 20 jan. 2011.

FLECK, N. G. Competição de azevém (Lolium multiflorum L.) com duas cultivares de trigo. Planta Daninha, v. 3, n. 2, p. $61-67,1980$

FLECK, N. G. et al. Resposta de cultivares de soja à competição com cultivar simuladora da infestação de plantas concorrentes. Sci. Agr., v. 8, n. 3, p. 213-218, 2007.

GALON, L. et al. Habilidade competitiva de cultivares de cevada convivendo com azevém. Planta Daninha, v. 29, n. 4, p. 771-781, 2011.

GOLDBERG, D. E.; LANDA, K. Competitive effect and response: Hierarchies and correlated traits in the early stages of competition. J. Ecol., v. 79, n. 4, p. 1013-1030, 1991. 
GUSTAFSON, D. J. et al. Competitive relationships of Andropogon gerardii (Big Bluestem) from remnant and restored native populations and select cultivated varieties. Funct. Ecol., v. 18, n. 3, p. 451-457, 2004

HAUN, J. R. Visual quantification of wheat development. Agron. J., v. 65, n. 1, p. 116-119, 1973.

HEAP, I. International survey of herbicide-resistant weeds. Disponível em: $<\mathrm{http}$ //Www.weed science.org $>$ Acesso em: 02 de nov. de 2012.

HUCL, P. Response to weed control by four spring wheat genotypes differing in competitive ability. Can. J. Plant. Sci., v. 78, n. 1, p. 171-173, 1997.
KOZLOWSKI, L. A. Período crítico de interferência das plantas daninhas na cultura do milho baseado na fenologia da cultura. Planta Daninha, v. 20, n. 3, p. 365-372, 2002.

LEMERLE, D. et al. Genetic improvement and agronomy for enhanced wheat competitiveness with weeds. Austr. J. Agric. Res., v. 52, n. 1, p. 527-548, 2001.

NI, H. et al. Oryza sativa plant traits conferring competitive ability against weeds. Weed Sci., v. 48, n. 2, p. 200-204, 2000 .

RIGOLI, R. P. et al. Potencial competitivo de cultivares de trigo em função do tempo de emergência. Planta Daninha, v. 27, n. 1, p. $41-47,2009$. 